\title{
Wenn schon Kindern der Schädel brummt
}

\begin{abstract}
Die Prävalenz von kindlichen Kopfschmerzen liegt bei etwa 50\%. Eine Umfrage der Deutschen Migräne- und Kopfschmerzgesellschaft ergab zudem, dass sieben von zehn Jugendlichen zwischen 13 und 18 Jahren in den vergangenen drei Monaten unter Kopfschmerzen gelitten haben. Wie kann man helfen?
\end{abstract}

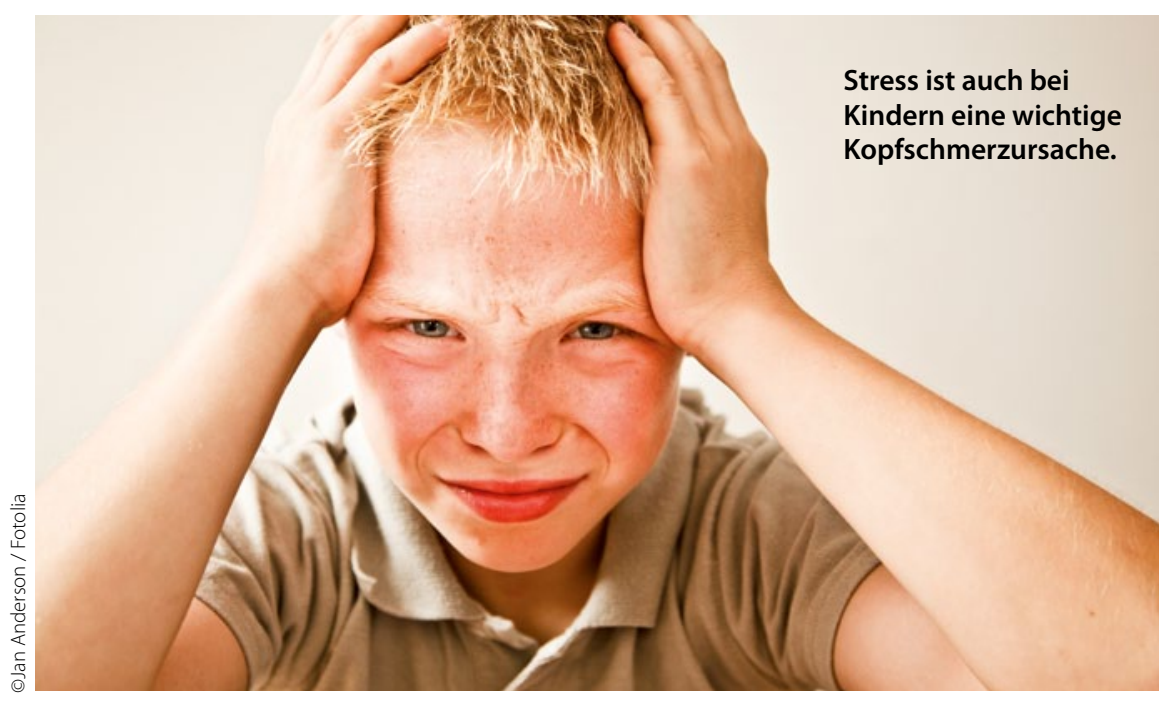

- Vor der Pubertät leiden öfter die Jungen unter Kopfschmerzen, danach mehr die Mädchen, sagte Dr. med. Andreas Oberle, Stuttgart. Oft sind damit auch sozialer Rückzug, Schlafprobleme, Versäumnisse in der Schule und Ängste verbunden. Eine Migräne beeinträchtigt die Lebensqualität ähnlich stark wie onkologische oder rheumatische Erkrankungen. Bei der Hälfte der Kinder persistiert die Erkrankung bis ins Erwachsenenalter.

\section{Vorsicht bei isolierter Aura}

Bei Kindern kommt die Migräne ohne Aura häufiger als bei Erwachsenen bilateral vor. Ebenfalls häufiger leiden Kinder an Migräne mit Aura: 15-30\% geben Aurasymptome wie Flimmerskotome, Parästhesien, Sensibilitäts- und Sprachstörungen an, die in der Regel den Kopfschmerzen vorausgehen. Tritt eine Aura aber isoliert auf, muss man hellhörig werden. „Es könnte sich um sekundäre Kopfschmerzen handeln, hinter denen sich $u$. U. eine dramatischere Ursache verbirgt", so Oberle. oder Triptane an mehr als zehn Tagen im Monat eingenommen werden.

\section{Kopfschmerzen nur, wenn Matheprüfung ansteht?}

„In der Diagnostik versuche ich, die Situation des Kindes einzuschätzen“, erklärte Oberle. Manchmal hilft es, wenn ein Kind zeichnet, wie es seine Kopfschmerzen empfindet. Auch ein Kopfschmerzkalender kann die Ursachenfindung unterstützen. Wichtige Informationen ergeben sich aus dem zeitlichen Verlauf oder der Frequenz, mit der die Kopfschmerzen auftreten. Passiert es nie in den Ferien, aber z. B. immer dann, wenn Mathematiktests anstehen, ist das ein wichtiger Hinweis auf die Ursache.

Die körperliche Untersuchung deckt klinische oder neurologische Auffälligkeiten auf. Relevante Punkte sind dabei der Kopfumfang (Perzentilensprung), neurokutane Erkrankungen, Traumata in der Anamnese, nächtliches Knirschen, schmerzhafte Nervenaustrittspunkte, Sehvermögen, Zeichen für Meningismus und der Zustand der Nackenmuskulatur.

\section{Therapie: zunächst ohne Tabletten}

Bei akuten Kopfschmerzattacken sollte die Stirn gekühlt werden und das Kind sollte sich hinlegen und versuchen $\mathrm{zu}$ schlafen. Erst wenn Allgemeinmaßnahmen nicht ausreichen, kommen Pharmaka in Betracht. An der Spitze steht im Kindesalter immer noch Ibuprofen (10$15 \mathrm{mg} / \mathrm{kg}$ ), gefolgt von Paracetamol oder ASS. Triptane wie Sumatriptan stellen erst bei Kindern ab 30 kg Gewicht eine Option dar. Antiemetika wie Domperidon spielen eine geringe Rolle.

Bei Spannungskopfschmerzen sollte man mit Medikamenten wie Ibuprofen oder Paracetamol sehr zurückhaltend agieren; meist gibt es Trigger, die sich vermeiden lassen. Pfefferminzöl auf die Stirn gerieben kann hilfreich sein.

$\mathrm{MB}=$ 